\title{
Greek plutonium haul raises smuggling fears
}

Quirin Schiermeier, Munich

The Greek authorities are stepping up investigations into the smuggling of nuclear material following the discovery of a cache of radioactive plates in the north of the country.

Around 350 plates containing a total of three grams of plutonium were unearthed last month in a forest near the city of Thessaloniki. But such a small amount is a long way from the several kilograms needed to build a nuclear weapon.

"The only explanation for their appearance is that they were smuggled into Greece by criminals hoping to find a gullible buyer," says Leonidas Kamarinopoulos, president of the Greek Atomic Energy Commission (GAEC).

The plates were found following an anonymous tip-off to police. They were taken to a nuclear research laboratory in Athens, where analysis by a GAEC team revealed the presence of plutonium-239 and traces of americium.

According to the Greek authorities, the mildly radioactive plates are probably machine components from eastern Europe. Kamarinopoulos believes that the plates were stolen from a paper plant, most probably in Russia, where devices containing plutonium are widely used as electrostatic eliminators. This technology is not used in the West.

But the circumstances of any planned smuggling deal remain hazy. An anonymous informant apparently told the police that members of the Bulgarian mafia had hidden the material in the forest. But it is not clear whether the couriers were still arranging to sell the plates, or seeking to dispose of them after failing to find a buyer.

Although there have been several reported cases of attempted plutonium trading in Germany, Bulgaria and Turkey, this is the first known case of such smuggling in Greece.

Given the incident's rather amateurish circumstances, Kamarinopoulos is inclined to dismiss it as isolated case. Nonetheless, the Greek government is taking it seriously, and says it will explore the possible existence of a larger channel of nuclear smuggling activity through Greece.

According to David Kyd, a spokesman for the International Atomic Energy Agency (IAEA) in Vienna, the discovery is "a potential health hazard, but certainly not a serious proliferation risk". As nuclear weapons need several kilograms of plutonium, he says: "No interested party would buy plutonium in the magnitude of a few grams, hoping that the dealer will come back with more."

The IAEA has sent a safety expert to Greece to assist the local authorities in decontaminating the spot where the plates were found. Meanwhile, 200 cubic metres of soil have been removed, and all water sources in the area have been sealed off. The vicinity is also being searched for any more radioactive material.

The IAEA has offered to help analyse the precise balance of plutonium isotopes in the material, which would help to track down its exact source.

Nuclear proliferation experts are cautious about judging the significance of the incident. "No matter how big the actual threat is, it is disturbing to see that some east European production and research facilities are not sufficiently safeguarded," says Spurgeon Keeny, president of the Washingtonbased Arms Control Association.

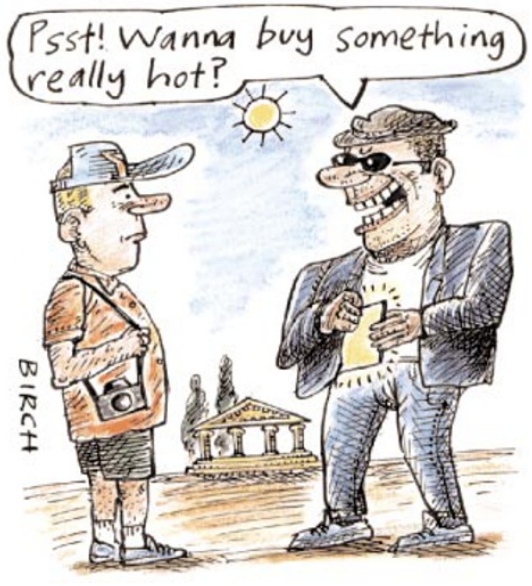

\section{Top research universities face up to gender bias}

\section{Steve Nadis, Boston}

The leaders of the top research universities in the United States are facing up to the fact that they have a problem with women.

Presidents, chancellors and provosts from nine élite institutions met up with 25 women academics last week at the Massachusetts Institute of Technology (MIT) to confront the issue of gender bias in science and engineering.

Representatives from the schools including the California Institute of Technology, Harvard, Princeton, Stanford and Yale - acknowledged that women researchers face substantial barriers to career advancement. Without promising any immediate specific actions, they vowed to work together to break these barriers down.

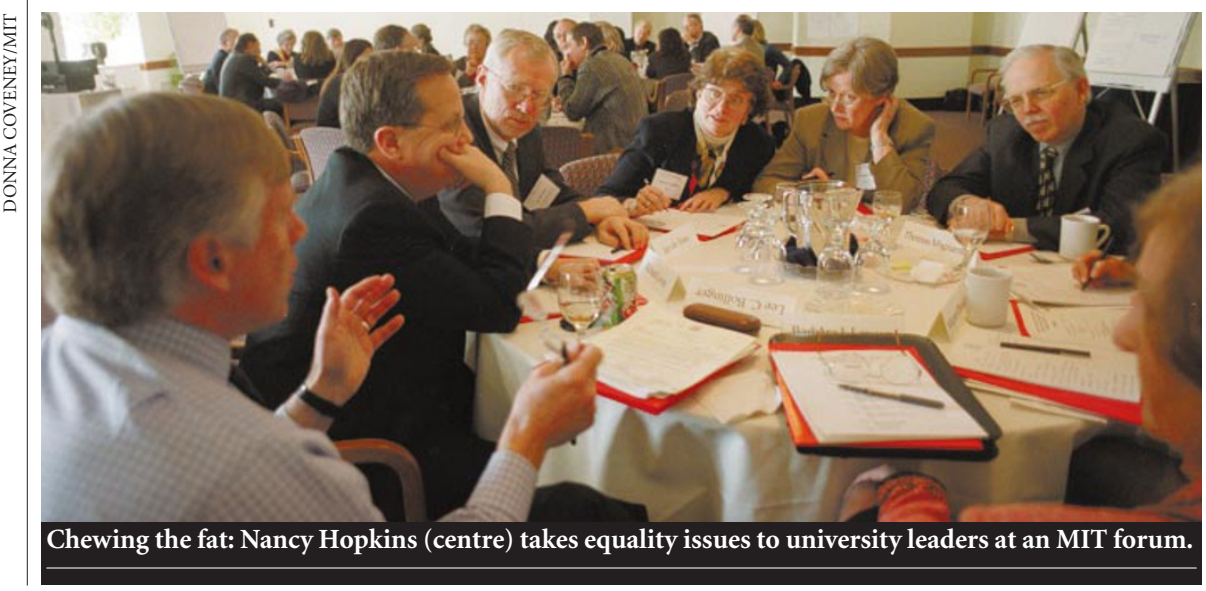

Biologist Nancy Hopkins, who has led the fight against discriminatory practices at MIT, describes the meeting as an "historic event-a milestone that I thought would never happen in my lifetime".

Harvard physicist Howard Georgi agrees. "The top institutions are the places where the [bias] problems may be the most serious because the faculty is the most competitive. If we can make inroads here, it will have an enormous impact," he says.

The participants pledged to go back to their institutions, collect information on factors such as hiring practices, salaries and committee membership, and then try to establish "a faculty whose diversity reflects that of the students we educate".

The group will reconvene in a year's time to collate their data and discuss what improvements, if any, have been made. The possibility of collective action will then be considered.

"The fact that we're all coming back a year from now creates some pressure to actually get something done," says MIT president Charles Vest, who organized the event. 